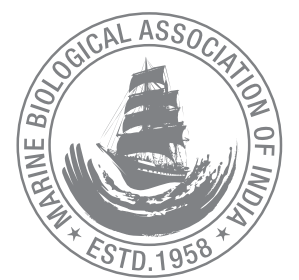

\title{
Impact evaluation of marine fisheries interventions among Tribal Fisher Commune of Car Nicobar Island, India
}

\author{
R. Kiruba-Sankar ${ }^{1 *}$, K. Lohith Kumar', J. Raymond Jani Angel², Shyam S. Salim³ , K. Saravanan', \\ P. Krishnan ${ }^{4}$, T. Ravikumar ${ }^{5}$ and S. Dam Roy ${ }^{1}$ \\ ${ }^{1}$ ICAR-Central Island Agricultural Research Institute, Andaman and Nicobar Islands. \\ ${ }^{2}$ ICAR-Central Institute of Brackishwater Aquaculture, Chennai. \\ ${ }^{3}$ ICAR-Central Marine Fisheries Research Institute, Kochi. \\ ${ }^{4}$ ICAR-National Academy of Agricultural Research Management, Hyderabad. \\ ${ }^{5}$ Fisheries College and Research Institute, Tamil Nadu Fisheries University, Thoothukudi. \\ *Correspondence e-mail: rkirubasankar@gmail.com
}

Received: 5 Nov 2018 Accepted: 19 May 2020 Published: 08 July 2020

Original Article

\begin{abstract}
Fisheries and tourism are two important sectors that provide livelihood and employment in the tropical Islands. Andaman and Nicobar group of Islands is a biodiversity hotspot in the Bay of Bengal inhabited by settler population along with indigenous tribal communities. The Nicobar tribal community is one among occupying the Nicobar group of Islands in the majority and are quite socialized tribal communities of the Islands. Agriculture, animal husbandry and fisheries are the major sectors that contribute to the livelihood and nutritional security of the Nicobar tribes. Traditional fishing activities have been a part of their culture over the years however, tribal youths were reluctant in taking up fishing as a profession considering the changing scenario and alternative employment options. To reinstate fisheries as a profession and to improve their livelihood and employment opportunities, interventions were carried out in Car Nicobar Island. The interventions were mainly aimed towards increasing fish catches, to expand their fishing grounds and to sensitize safe fishing and navigation practices. Fishing inputs such as modern fishing boats, GPS and outboard engines were provided as inputs to tribal fishers based on the outcome of an expert consultation meeting. Structured questionnaires were prepared to analyze the impact of the interventions. The results indicated that the interventions led to a significant improvement $(p<0.001)$ in the expansion of their fishing grounds $(3.47 \pm 0.2 \mathrm{~km})$, reduced time
\end{abstract}

spent to reach the fishing grounds $(2.3 \pm 0.25$ hour) and increased catch per unit effort $(7.93 \pm 1.23 \mathrm{~kg} /$ boat $)$. This study shows that the targeted interventions coupled with awareness and sensitization programmes could make fishing activities profitable, attractive and can motivate the unemployed youths to opt for fishing as a profession.

Keywords: Nicobari tribes, fishing, employment, subsistence, livelihood

\section{Introduction}

The Andaman and Nicobar archipelago is a group of 572 Islands which encompasses 0.6 million $\mathrm{km}^{2}$ of Exclusive Economic Zone (EEZ), which accounts for $30 \%$ of India's total EEZ (Arif, 1983; Alagaraja, 1987; ANDFISH, 2005). Nicobar district is a group of 22 Islands predominantly populated with the aboriginal Nicobari tribe. Nicobari represent over $90 \%$ of the total tribal population of these Islands. Car Nicobar Island is the district headquarters which was predominantly inhabited by Nicobari population. A small chunk of the Nicobari population also lives in Little Andaman Island alongside the non-tribal population. Car Nicobar is a small flat Island and is vulnerable to climate change events. The Indian Ocean 
Tsunami during 2004 caused huge devastation in Car Nicobar Island resulting in loss of livelihood and property. Car Nicobar Island has rich biodiversity which is very unique and integral to the cultural setting of the tribal fishers (Ravikumar et al., 2015). Agriculture, fisheries and animal husbandry are the mainstays of Car Nicobar Island but those resources are not fully tapped to their potential considering several constraints (Ravikumar et al., 2016). Fishing activities were carried out on subsistence level using primitive fishing gears such as spears, bow and arrow, ichthyotoxins from plant origin and recently by other fishing gears such as cast net, gillnet, beach seine and hook and lines. Majority of the tribal fishermen use traditional fishing craft, locally known as hodi (dugout canoe with outrigger), for fishing in the nearshore waters around the Island. Few fishing crafts of wooden and fibre reinforced plastic (FRP) boats fitted with outboard and inboard engines were also used by tribal fishermen. Ahmed et al. (2013) noted that 79 traditional fishing crafts and 14 motorized boats were in possession of Nicobarese in Car Nicobar. Use of navigational aids, such as Global Positioning System (GPS) was not in practice among the tribal fishermen of Car Nicobar. Mostly they rely on their indigenous traditional knowledge and navigation skills. Though the Nicobar Islands possess good fishery potential, they remain underexploited as the tribal fishermen do not venture long distances and are not aware of modern fishing methods. Another major reason for under exploitation and low fish catches is that fishing is seen mostly as subsistence activity and not commercial one. The contribution of Nicobar group of Islands to the marine fishing sector is very low compared to the Andaman group of Islands contributing less than $2 \%$ to annual marine landings (Fig. 1). The estimated marine fisheries potential of ANI is 1.48 lakh tonnes, whereas fish harvest remains at 39,284 tonnes in 2017-18 (Department of fisheries, Andaman \& Nicobar Administration). Lack of skilled fishermen, underutilization of the offshore fisheries, weak market links, inadequate

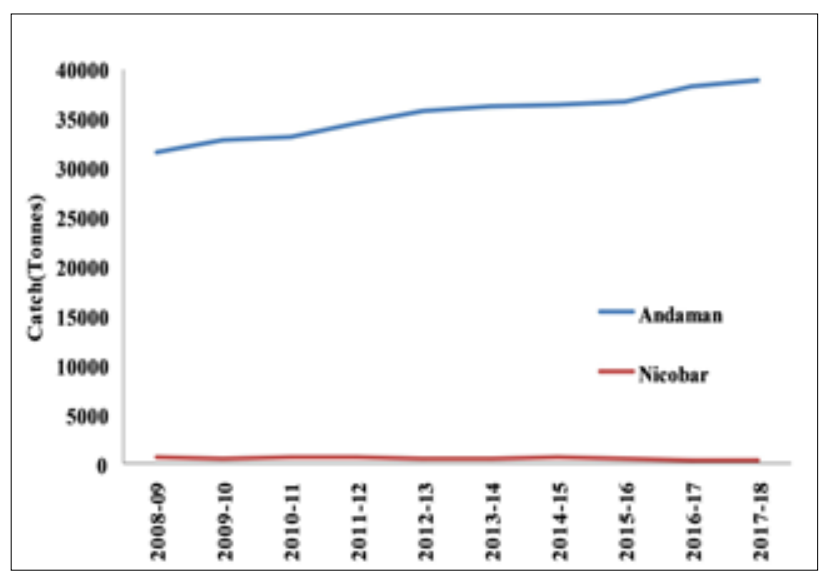

Fig. 1. Marine fish catches from Andaman and Nicobar group of Islands Source: Department of fisheries, Andaman \& Nicobar Administration. infrastructure and insufficient logistical support are some of the reasons for lower fish landings in the Islands. Few scientific interventions such as potential fishing zones advisories have been proven to be beneficial in increasing the fish catches for fishermen following the advisories (George et al., 2011; 2013; 2014). The Nicobari tribes were actively involved in fishing activities and are seafarers until 2004 mega earthquake and Tsunami that struck the Indian Ocean, which caused a major impact on the mindset of tribal communities as the fear of sea still exists among the tribes due to open sea conditions. The issues identified within Nicobar fishing community is the limited knowledge on navigation, lack of distance fishing activities, lack of upgradation in fishing gears and crafts and inadequate knowledge on responsible fishing practices and sustainable fisheries. Lack of market links and the isolated conditions were discouraging factors for the tribal fishers as they fish only what is required to eat.

\section{Material and methods}

\section{Study Area}

Nicobar district is a group of 22 Islands and is separated from the Andaman Islands by the ten-degree channel. The Nicobar Islands are divided into three subdivisions namely Car Nicobar, Nancowry and Great Nicobar (Roy et al., 2017). The study was conducted in Car Nicobar Island (Fig. 2). Maps used were prepared using QGIS 2.16 version, an open-source GIS software.

\section{Approach}

The study preceded with a regional workshop and expert meet organized in 2012 as 'Consultation on revitalizing Andaman and Nicobar Tribal fishers through Fish Harvest and Post-Harvest Technologies (CRAFT)' which specifically suggested the course of interventions to be followed up in

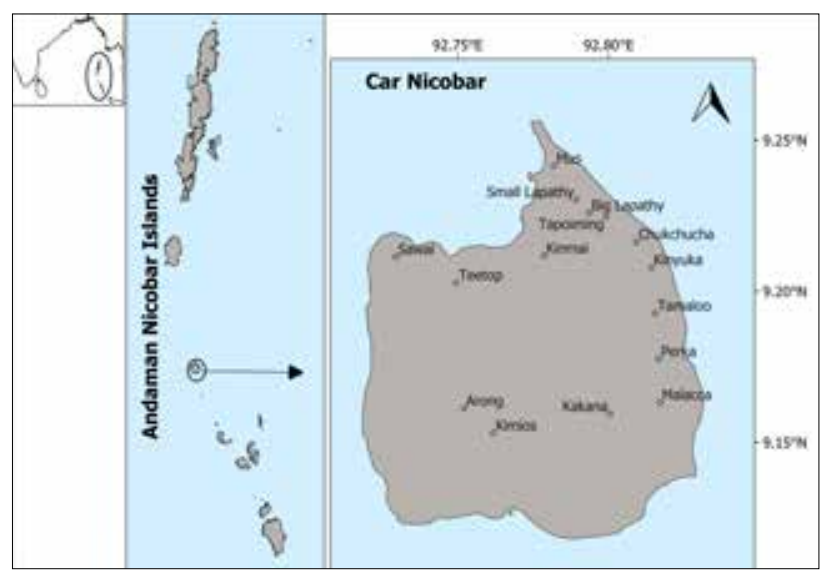

Fig. 2. Map showing Car Nicobar Island, and the tribal villages intervened 
marine fishery sector of Nicobar tribal community. Scoping surveys and field visits targeted at resources and resource users were conducted in Car Nicobar Island to assess the existing fishing activities and to sensitize the need for intervention among the tribal fishing community. Focused group discussions were held with the tribal captains to ascertain their requirements towards improving their existing fishing activities were taken up with the introduction of improved fishing crafts, use of outboard motor (OBM) engine to fit in their traditional hodi and global positioning system (GPS). The tribal fisher interactions assessed their basic requirements and expectations to undertake fishing activities. The intervention approach involved three phases such as pre-intervention, intervention and post-intervention phase. After the pre-intervention phase, fishing inputs (Table 1) were provided and demonstrations along with training and awareness were conducted on the use of the inputs during the intervention phase. During the post-intervention phase, the developments were recorded through field visits and interviews.

Table 1. Details of fishing inputs provided to the tribal fishermen

\begin{tabular}{lll}
\hline S. No. & Fishing input provided & Purpose \\
\hline 1 & $\begin{array}{l}\text { FRP Motorised Boat (30 } \times 5.5 \times 2.25 \\
\text { m) dimension with 15hp OBM } \\
\text { engine, life saving equipments, fire } \\
\text { extinguisher and fish hatch with } \\
\text { detachable canopy for shade }\end{array}$ & $\begin{array}{l}\text { To venture in long distance fishing } \\
\text { with safety features, to introduce the } \\
\text { tribal fishers to modern fishing boats } \\
\text { with endurance for long and safe } \\
\text { fishing. }\end{array}$ \\
\hline 2 & 4HP Out Board Motor (OBM) Engine & $\begin{array}{l}\text { Motorization of traditional fishing } \\
\text { crafts (hodi) }\end{array}$ \\
\hline 3 & Global Positioning System (GPS) & $\begin{array}{l}\text { To assist the tribal fishers to navigate } \\
\text { in and around the Islands for safe } \\
\text { navigation and profitable fishing }\end{array}$ \\
\hline 4 & Life Jackets & Safety at sea \\
\hline 5 & Iceboxes & Preserve the catch onboard \\
\hline
\end{tabular}

\section{Impact studies}

To assess the impact of the intervention approach the economic efficiency of the fishing operations carried out by the village council during the period (November 2013 to May 2015) was done. A total of 30 fishers, represented from fifteen villages of Car Nicobar who were regularly undertaking fishing activities with the provided inputs such as 4hp outboard engines and the FRP modern fishing boat were used for data collection. A structured schedule was developed to elicit information on the distance travelled from the coast for fishing, time spent for fishing, fish caught and catch composition were collected to arrive at catch and revenue estimates. The catch per unit effort (CPUE) was calculated by dividing the total catch caught per day by fishing hours and was expressed as fish caught per hour (Geetha et al., 2014). The tribal fishermen rarely sell their fish catches, however, to study the economic impact the revenue generated by fishing was calculated by multiplying the quantity of fish caught and the average price of fish in the local market. Paired student's t-test was used to compare the means during pre and post-intervention. Statistical analysis was performed using SPSS ver. 16.0 and differences were considered to be statistically significant at $p<0.05$. Data are presented as mean \pm standard error (SE).

In addition, the impact analysis also attempted at assessing social, economic and technical changes of tribal fishers due to interventions. The perceptions leading to the usage of the inputs and effects of improved fish production technology, satisfaction levels of the tribal fishers due to interventions were also ranked using the Garrette ranking method.

\section{Results and discussion}

The interventions struck a positive change in the mindset of tribal community evident from the rise in fish catches and the expansion of their fishing grounds. The comparison of the movement of fishers to offshore for fishing activity shows that there is a significant improvement in the fishing range with the intervention ( $t=-17.17, p=<.0001)$. There is an increase of $3.47 \pm 0.2 \mathrm{~km}$ range in fishing with the intervention. There was a significant reduction of $2.3 \pm 0.25$ hour in time spent for scouting and fishing after the intervention ( $t=9.04, p=<0.001)$. The total fish catch per boat significantly increased from 31.17 $\pm 1.06 \mathrm{~kg}$ to $39.1 \pm 0.89 \mathrm{~kg}$ due to the intervention ( $\mathrm{t}=-10.91$, $\mathrm{p}<0001)$. An increase of $7.93 \pm 1.23 \mathrm{~kg} / \mathrm{boat}$ was recorded as a result of the intervention in CPUE (Fig. 3). The summary of fishing trips conducted and revenue earned by the Nicobari tribal community are given in (Table 2).

The impact assessment analysis through questionnaires collected through the surveys revealed that the tribal fishermen are convenient with the interventions and there is an improvement in the social status and economic benefits

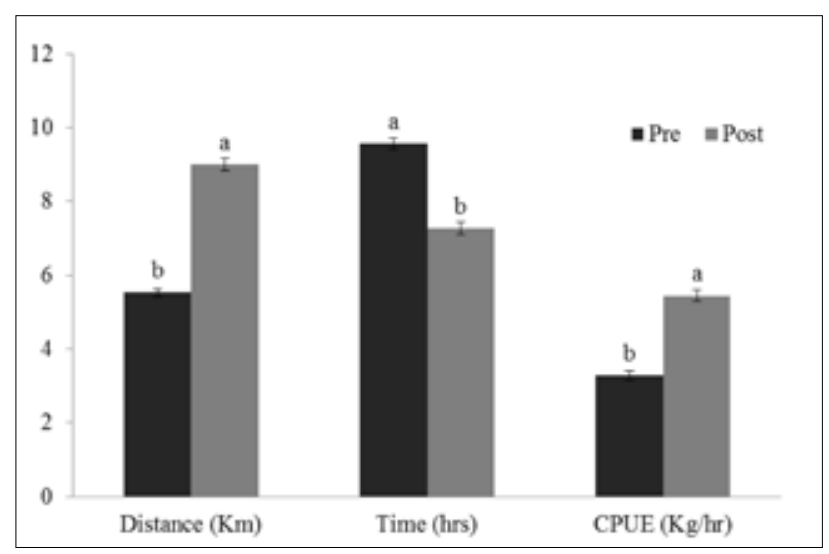

Fig. 3. Interventions and their impact in terms of distance, time and catch per unit effort (CPUE) during pre and post-intervention 
Table 2. Details of fishing trips conducted using FRP fishing boat

\begin{tabular}{lllll}
\hline Duration & $\begin{array}{l}\text { Fishing trips } \\
\text { undertaken }\end{array}$ & Fish catch/ trip & $\begin{array}{l}\text { Average economic value of the fish } \\
\text { caught at an average of } 125 \mathrm{~kg} / \text { trip }\end{array}$ & Fishes caught \\
\hline $\begin{array}{l}\text { November, } 2013 \text { to May, } 2015 \\
\text { (18 months) }\end{array}$ & 112 & 100-150 kg & Rs. 18,750/- & $\begin{array}{l}\text { Tunas, sharks, groupers, lethrinids, snappers, marlins, } \\
\text { barracuda \& carangids* Considering the average market price } \\
\text { of fish at Rs. 150/ kg. }\end{array}$ \\
\hline
\end{tabular}

through fishing activities. The age group of the respondents for impact assessment study was dominated by $60-70$ year old fishers (43.33\%) followed by $50-59$ years (30 \%), 40-49 and $30-39$ years $(10 \%$ each), $<30$ and $>70$ years $(3.33 \%$ each). Their education level was in the order of primary $(50 \%)$, high school (40\%), higher secondary $(6.67 \%)$ and graduate (3.33\%) level. Their experience in fishing was in the order of $35-45$ years $(40 \%), 45-55$ years $(26.67 \%), 25-35$ years $(16.67$ $\%),<25$ years $(13.33 \%)$ and $>55$ years $(3.33 \%)$. Level of awareness on fishing technologies during pre-training varied from very low to very high for different parameters such as the use of OBM (high-33.33\%); GPS (very low-100\%); fishing gears (very high -70\%); life jacket (high-60\%); fish holds (very high-86.67\%) and ice (very low-76.67\%). On the other hand, post-training improved the level of awareness as very high for various parameters such as the use of OBM $(100 \%)$, GPS $(100 \%)$, fishing gears $(100 \%)$, life jacket $(100 \%)$, fish holds $(100 \%)$ and as high for the use of ice $(60 \%)$. The satisfaction level of the tribal fishers through interventions revealed a high level of satisfaction as shown in (Table 3).

Behavioral changes/perception observed from the fishers post-training were assessed across three domains viz., social, economic and technical changes as shown in (Table 4). Among the different social, economic and technical changes of tribal fishers due to interventions assessed it was found

Table 3. Satisfaction level of the tribal fishers due to interventions

\begin{tabular}{llll}
\hline S. No. & Parameters & Score (\%) & Rank \\
\hline 1 & Training and support & 18.98 & III \\
\hline 2 & Motivation/ Leadership & 11.20 & IV \\
\hline 3 & Accomplishments/ Satisfaction & 10.20 & $\mathrm{~V}$ \\
\hline 5 & Working environment & 5.01 & $\mathrm{VI}$ \\
\hline 6 & Economic benefits & 28.96 & $\mathrm{I}$ \\
\hline
\end{tabular}

that imparting leadership skills (33.36) followed by improved social status (22.12) and improved networking (20.89) were found to be the most important social changes. The improved income (32.63) followed by the identification of a better income source (25.36) and rational decision making (20.15) were the most important economic changes as perceived by the fishers due to the interventions. The technical changes were mostly manifested by improved perceptions on better access to information using GPS (34.63) followed by improved knowledge (21.56) (Table 4).

The assessment on the perception of tribal fishers on the use and effects of improved fish production technology indicated that using improved fisheries technologies saves time (28.56), improved technology caters to the educated (19.56), requires high labour requirement (15.99) among many parameters selected (Table 5). Few problems like the adoption of tribal fishers to new fishing methods, high cost of fuel coupled with uncertain availability, maintenance cost and lack of engine spares were some of the issues faced by tribal fishers. Fuel availability was one of the major limitations for tribal fishers to undertake frequent fishing activities. Unavailability of engine/ machinery spare parts and repair facilities were also some of the technical constraints faced by tribal fishers in the Islands. Motivated by the interventions the tribal fishers also requested for additional inputs such as life jackets, snorkeling kit and auxiliary fuel tank to take up fishing activities. The feedback collected from the villagers indicated that their dependency on imported fish sold in the local markets has been reduced to a greater extent. The fishing boat provided as input through the intervention was also hired by other villages of Car Nicobar to carry out fishing activities which are a positive outcome of our intervention.

The interventions carried out and the overall fishing activities of the Car Nicobar tribes are shown in (Fig. 4). The approach of

Table 4. Social, economic and technical changes of tribal fishers due to interventions

\begin{tabular}{|c|c|c|c|c|c|c|c|c|}
\hline Social & Score $(\%)$ & Rank & Economic & Score $(\%)$ & Rank & Technical & Score $(\%)$ & Rank \\
\hline Networking & 20.89 & III & Improved income & 32.63 & 1 & Fishing operations & 5.06 & V \\
\hline $\begin{array}{l}\text { Improved social } \\
\text { status }\end{array}$ & 22.12 & II & Rational decision making & 20.15 & III & Improved knowledge & 21.56 & III \\
\hline Leadership & 33.36 & I & Identification of a better source of income & 25.36 & ॥ & Better access to information on GPS & 34.63 & I \\
\hline Independence & 15.23 & IV & Independence & 16.02 & IV & Improved techniques of life saving devices & 23.12 & $\|$ \\
\hline Changed attitudes & 8.4 & V & Linkages with other fishermen & 5.84 & V & Voyage fishing & 15.63 & IV \\
\hline
\end{tabular}


Table 5. Perception to use and effects of improved fish production technologies

\begin{tabular}{llll}
\hline S. No. & Parameters & Score (\%) & Rank \\
\hline 1 & Using improved fisheries technologies saves time & 28.56 & I \\
\hline 2 & $\begin{array}{l}\text { Fish farmers' uses of improved technologies increase } \\
\text { profit/ improved income via higher yield/ harvest }\end{array}$ & 10.1 & $\mathrm{~V}$ \\
\hline 3 & Improved technologies are only for the educated & 19.56 & $\mathrm{II}$ \\
\hline 4 & They are incompatible & 5 & $\mathrm{VII}$ \\
\hline 5 & Have high labor requirement & 15.99 & $\mathrm{III}$ \\
\hline 6 & Improve technologies are too costly & 8.76 & $\mathrm{VI}$ \\
\hline 7 & $\begin{array}{l}\text { Using improved fisheries technologies lead to high } \\
\text { product losses }\end{array}$ & 12.03 & $\mathrm{IV}$
\end{tabular}

Nicobar tribes towards the sea is simple, primitive, indigenous and diverse (Ravikumar et al., 2016) with a lot of indigenous traditional knowledge. Fishing in open sea demands greater skills and they are inherited over the years through their ancestors (Ahmed et al., 2013). Nicobari tribes sensitize and advocate the indigenous traditional knowledge to the younger generation, however, there is a subtle threat of

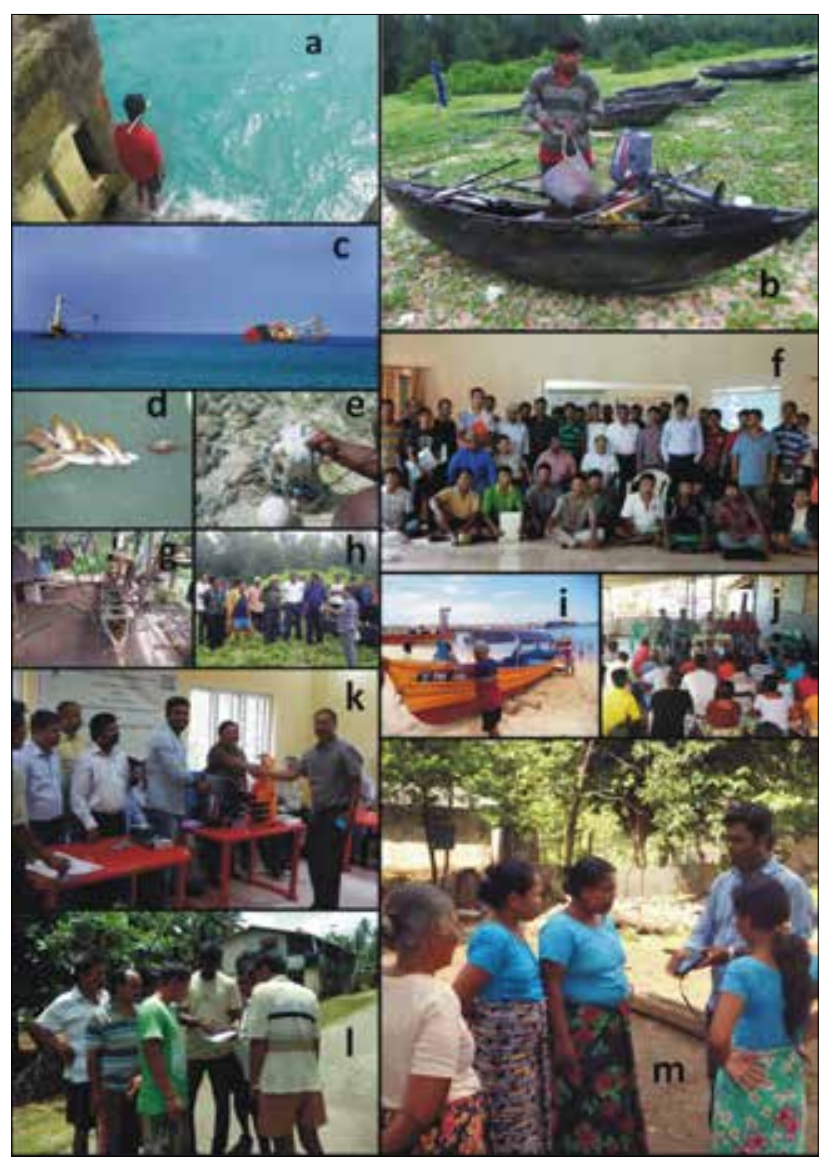

Fig. 4. (a): Nicobari tribe about to venture into the sea with a spear; (b): fishermen with a local boat, Nicobari Hodi; (c): a shipwreck acts as fish aggregating area; (d-e): typical subsistence fish catches; (f): Group interactions with tribal fishers $(\mathrm{g})$ : traditional Hodi construction by fishers; (h-m): participatory discussion with the team; supply of outboard engine; on-field demonstration of GPS to women and men. these skills and knowledge getting lost due to the increasing pace of urbanization and social exposure (Ravikumar et al., 2015). Batti Malv, an Island close to Car Nicobar was known to be a rich fishing ground and the Nicobar fishermen used to fish there often. However, there were few incidences of fishermen reportedly missing due to wrong navigation practices as informed by the tribal fishers during our preintervention period. Post-intervention feedbacks revealed that such incidents were not reported in later stages as their navigation skills were well improved and those skills were also disseminated to other tribal fishers. Our interventions also involved training of women fishers and children in GPS navigation techniques as evident in (Fig. 4).

Scientific interventions among tribal fishers should augment economic developments in parallel with the preservation of their traditional practices and cultural heritage. Marine fisheries sector holds immense potential for Nicobar tribes in providing livelihood, employment and food security. Due to low fishing activities in the Nicobar group of Islands, there is also increasing incidences of marine poachers approaching these Islands from nearby countries to exploit the valuable marine resources like shells, sea cucumbers and fishes (Kiruba-Sankar et al., 2019). There is an imminent need to aggressively protect the marine waters and sustainably harness the resources for economic and livelihood benefits of the Nicobar fishers. Subsistence fishing activity could be satisfactory for Nicobar tribes in providing daily food security however, it may not be promising for tribal youths seeking employment opportunities. Car Nicobar local market imports marine fishes from the nearby Andaman group of Islands. This critical gap can be advantageous for the Nicobari fishers as they could reduce the import of marine fishes by sustainably harnessing the resources around their Island. The current set of interventions gave a positive outlook to the marine fishing sector and to see fishing as a promising profession among Nicobari tribes. Pursuing the Nicobari tribes with continuous motivation and sustained efforts through timely exposure to innovative fishing methods and advanced fishing tools could upgrade their fishing practices and uplift the economy of Nicobari tribes through the rise in employment opportunities and economic development through the marine fishery sector.

\section{Acknowledgements}

The works and interventions were carried out under the Tribal Sub Plan (TSP) programme of ICAR-Central Island Agricultural Research Institute, Port Blair. The authors sincerely acknowledge the indispensable support of the Tribal council of Nicobar group of Islands including Tribal captain, headman and other tribal households for providing excellent support and cooperation throughout the field work phases and interventions. The 
support and kind guidance of the Director, ICAR-CIARI and the unconditional assistance rendered by the Programme coordinator, staffs of KVK, Car Nicobar and Department of Fisheries, A\&N Administration is also gratefully acknowledged. The authors also acknowledge the assistance of Director of fisheries, Andaman\& Nicobar Administration for providing data on marine fish landing.

\section{References}

ANDFISH. 2005. Draft roadmap for the development of fisheries in Andaman and Nicobar Islands $87 \mathrm{pp}$.

Ahmed, S. K. Z., T. Ravikumar, P. Krishnan and S. Jeyakumar. 2013. Traditional fishing crafts and gears used by the Nicobari tribes in Car Nicobar. Indian J. Tradit Knowl., 12(1): 144-148

Alagaraja, K. 1987. An appraisal of the marine fisheries in the island territories Lakshadweep and Andaman and Nicobar Islands. CMFRI Special Publication Number 39: 22 pp.

Arif, M. M. 1983. Fisheries of Andaman and Nicobar Islands. ICLAM Newsletter, 6(4): $7-9$.

Geetha, R., R. Narayanakumar, S. S. Salim., N. Aswathy., S. Chandrasekar., V. S. Ragavan and I. Divipala. 2014. Economic efficiency of mechanized fishing in Tamil Nadu- a case study in Chennai. Indian J. Fish., 61(4):31-35.
George, G., P. Krishnan, Kamal-Sarma, R. Kirubasankar, M. P. Goutham-Bharathi, M. Kaliyamoorthy, V. Krishnamurthy and T. S. Kumar. 2011. Integrated potential fishing zone (IPFZ) forecasts: a promising information and communication technology tool for promoting green fishing in the Islands. Ind. J. Agri. Econ. 66(3):513-519

George, G., K. Sarma, G. Bharathi, M. Kaliyamoorthy, P. Krishnan and R. Kirubasankar 2014. Efficacy of different modes in disseminating Potential fishing zone (PFZ) forecasts- a case study from Andaman and Nicobar Islands. Indian J. Fish., 61(1): 84-87.

George, G., P. Krishnan, S. D. Roy, K. Sarma, M. P. G. Bharathi, M. Kaliyamoorthy, V. Krishnamurthy and T. S. Kumar. 2013. Validation of Potential Fishing Zone (PFZ) forecasts fromAndaman and Nicobar Islands. Fish. Technol., 50:1-5.

Kiruba-Sankar, R., K. L. Kumar, K. Saravanan and J. Praveenraj. 2019. Poaching in Andaman and Nicobar Coasts: insights J. Coast. Conserv., 23:95-109.

Ravikumar, T., P. Krishnan, N. Ram, R. K. Sankar, S. D. Roy, S. K. Z. Ahmed and N. Neethiselvan, 2015. Hodi, a traditional craft of Nicobari tribe. Indian J. Tradit. Knowl., 1(1):161-168.

Ravikumar, T., N. Ram, P. Krishnan, R. K. Sankar, V. Sachithanandam and S. D. Roy. 2016. Subsistence fishing methods of Nicobari tribes using traditional knowledge. Journal of Marine and Island Cultures, 5:79-87.

Roy, S. D., P. Krishnan, A. Velmurugan, A. Anand, G. George, R. K. Sankar, and T. P. Swarnam. 2017. Wetlands of tropical Islands under changing climate: A case from Nicobar group of Islands 205-224. In Prusty A. K. et al., (eds). Wetlands Science. Perspectives from South Asia. Springer, 587pp. 